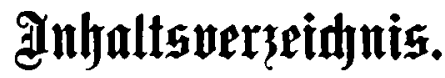

Cinleitung.

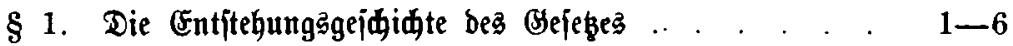

§ 2. Die Brundzüge ber ßhebührenorbnung . . . . . . 6-15

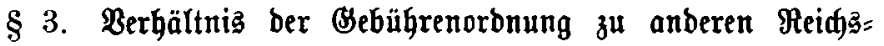
gejęzen . . . . . . . . . . . . . . . . $15-17$

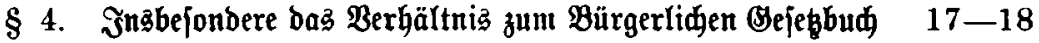

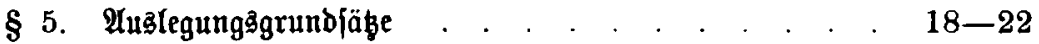

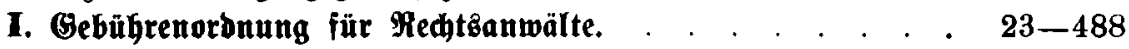

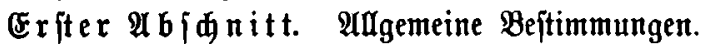

$\$ 81-8$. . . . . . . . . . . . . . . . 23-77

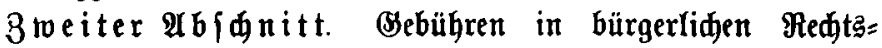
ftreitigfeiten.

Borbemerhungen . . . . . . . . . . . . . . . . . . . 78

$\S \S 9-52$. . . . . . . . . . . . . . . . $78-361$

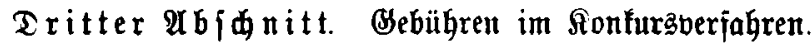

Borbemerfurgen . . . . . . . . . . . 361-365

$\$ \S 53-62$. . . . . . . . . . . . . . . 365-378

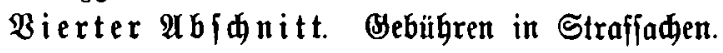

Borbemerfungen . . . . . . . . . . . . . . 378-388

$\$ 63-75$. . . . . . . . . . . . . . . $388-419$

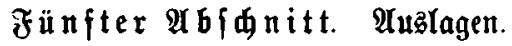

Borbemerfungen . . . . . . . . . . . . . . 420-421

$\$ 876-83$. . . . . . . . . . . . . . . . $422-442$

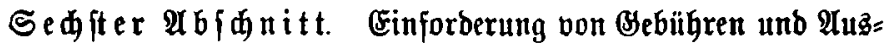
lagen.

Borbemerfung . . . . . . . . . . . . . . 442-443

$\$ 88-86$. . . . . . . . . . . . . . . . $443-450$

Siebenter $\mathfrak{A b}$ 出itt. Shlubbeftimmungen.

Borbemerfung . . . . . . . . . . 450-451

$\$ 87-95$. . . . . . . . . . . . . . . . $451-488$

II. Gebühren=:abellen. . . . . . . . . . . . . . . . . 489-495

Anbang I. Entwurf einea Befétez betr. Änberungen . . der Be= bührentorbnung für Redtsanmälte . . . . . . . . . . . 496-498

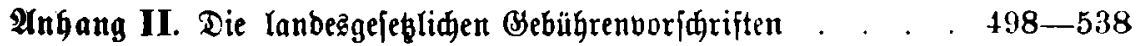




\section{A. Pren⿳⺈冂n.}

Befes, enth. bie lanbeşgef. Boriđriften über bie Bebübren ber

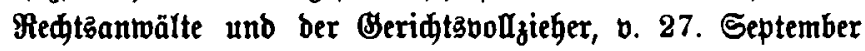
1899 , in ber Faffung ber Befanntmadung v. 6 . Ottober $1899 \quad 498-519$ Bebübren=Tabellen

\section{B. Bayern.}

1. Berorbn., bie Bebüfren ber Medtzantwälte in ben QAngeleg. ber Medtappllege betr., v. 26. März 1902.

2. Beroron., bie Bebühren ber Medțantoälte in ben Angeleg. ber Berw. u. b. Berwaltunģ̈redtspîlege betr., v. 26. März 1902 $527-530$

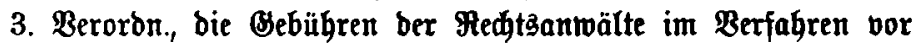
bem $\Re$. Ranbeşberficherungsamte betr., v. 4. April 1902 . . 530

\section{Sönigreid Sadjien.}

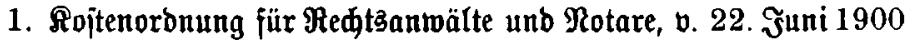

2. Berorbn., betr. bie Bebühren ber Reditsantwälte in bem Ber= fahren vor bem Lanbesperfiderungsamt, v. 27. Februar 1902

\section{D. $\mathfrak{B}$ ürttemberg.}

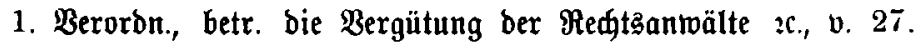
September 1879

2. Berorbn., betr. eine (Seb.D. für Bemeinbegeriळte, v. 28. Juni 1902

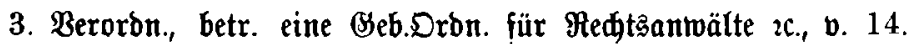
Rovember 1899 .

4. Berfïg., betr. bie Bebühren 2c. im Berfahren vor bem \&anbez= Berfiđerungąamt, v. 22. Эanuar 1902

\section{E. Baben.}

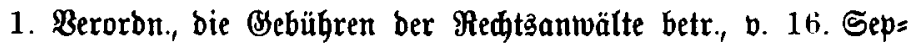
tember 1879

2. Beroron., v. 8. Dftober 1884

3. Berorbn., bie Bebühren im Berfahren vor bem Sanbeşber= fiderungånt betr., v. 14. Januar 1902

\section{F. Überïnt}

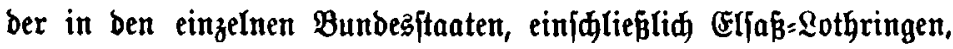
erlaffenen lanbesgefebliagen Borjariften über die Bebühren ber Reḑtzanwoülte 